\title{
Synthesis, Growth and Characterization of an Organic Material: P-Chloroanilinium Ethanoate
}

\author{
R. Sakunthaladevi ${ }^{1,2}$, L. Jothi ${ }^{3^{*}}$ \\ ${ }^{1}$ Department of Physics, Trinity College for Women, Namakkal, India \\ ${ }^{2}$ Research Scholar, Periyar University, Salem, India \\ ${ }^{3}$ Department of Physics, Namakkal Kavignar Ramalingam Government Arts College for Women, Namakkal, India \\ Email: *jothilakshmanan@gmail.com
}

How to cite this paper: Sakunthaladevi, R. and Jothi, L. (2020) Synthesis, Growth and Characterization of an Organic Material: P-Chloroanilinium Ethanoate. Journal of Minerals and Materials Characterization and Engineering, 8, 133-148.

https://doi.org/10.4236/jmmce.2020.83009

Received: April 29, 2020

Accepted: May 24, 2020

Published: May 27, 2020

Copyright $\odot 2020$ by author(s) and Scientific Research Publishing Inc. This work is licensed under the Creative Commons Attribution International License (CC BY 4.0).

http://creativecommons.org/licenses/by/4.0/

\begin{abstract}
Aromatic organic material of P-Chloroanilinium ethanoate (CAE) has been synthesized by condensation process using methanol as a solvent. The synthesized product is allowed to evaporate slowly at room temperature and crystals of cell dimension $25 \times 29 \times 10 \mathrm{~mm}^{3}$ were grown. The grown material was subjected to single crystal X-ray diffraction to obtain the cell parameters. The presence of functional groups in the grown material was confirmed by Fourier transform infrared and Fourier transform Raman spectral studies. The UV-VIS absorption spectrum reveals that the material has lower UV cut-off wavelength at $337 \mathrm{~nm}$. Using the Kurtz Perry Powder method, the NLO activity was confirmed. Mechanical strength of the crystal was estimated by Vickers micro hardness test which shows that the material belongs to the soft category. The thermal behavior of the material was investigated by using thermo gravimetric and differential scanning calorimetric analyses.
\end{abstract}

\section{Keywords}

X-Ray Diffraction, Linear and Non-Linear Optical Studies, Mechanical Parameters

\section{Introduction}

In recent years, organic electron donor-acceptor or charge transfer complexes fascinated much attention owing to their high potential applications in the field of optical signal processing, color displays, frequency conversion, photonics, laser remote sensing, organic superconductors, molecular electronics, electro-optical amplitude modulation, high density optical data storage, ultra-compact lasers, optical switching, optical parametric generation and biophotonics [1] [2] [3]. 
Aniline and its related structures are widely studied because of its importance in many pharmaceutical, electro-optical and several other social applications like production of dyes and pesticides [4]. P-chloroaniline is an organochloric aniline compound with molecular formula $\mathrm{C}_{6} \mathrm{H}_{4} \mathrm{NH}_{2} \mathrm{Cl}$. Already synthesis, growth and characterization studies of organic nonlinear optical material 4-chloroaniline single crystal were reported [5]. Molecular ionic simple complex crystals of an organic molecule should have large second order hyperpolarizability to exhibit good nonlinear optical properties and show unique to the crystal structure. The distinct features of molecular ionic crystal give empathizing correlation between the crystal packing and physical properties [6]. Ethanoic acid is one of the well-known carboxylic acids promoting molecular self-assembly by means of strong hydrogen bonding through its carboxylic acid group and the ring substituted amino group of p-chloroaniline. Strong hydrogen bonds occur due to the polarizable hydrogen atom covalently bonded to an electron with drawing donor oxygen atom and interact with partially negatively charged and comparatively less polarizable acceptor nitrogen atom, which will also increase the molecular hyperpolarizability [7] [8]. Even though many works using aldehydes, substituted aldehydes with p-chloroaniline had been already reported [9]-[15], best of our knowledge no work had been done with p-chloroaniline with ethanoic acid. However, in this paper, we report first time the synthesis, growth and characterization of $\mathrm{p}$-chloroanilinium ethanoate (CAE) ionic crystals and investigated the linear and nonlinear, optical, mechanical, and thermal properties of the grown CAE crystal.

\section{Experimental Procedure}

\subsection{Material Synthesis}

The solubility studies in different solvents showed that the titled compound was insoluble in water and highly soluble in ethanol and methanol. P-Chloroanilinium ethanoate (CAE) were synthesized by condensation process using methanol as a solvent because the growth rate of the crystal was well it. High purity chemicals P-Chloroaniline and Ethanonic acid were purchased from Loba chemicals that were used for this synthesis. The equimolar ratio of 4-Chloroaniline and Ethanonic acid was refluxed by methanol solvent and condensed about 7 hours with the temperature of $80^{\circ} \mathrm{C}$, to get the saturated solution of CAE. The solution was filtered in a beaker to remove any impurities present in it, using a Whatman filter paper.

\subsection{Material Synthesis}

Consecutively, the beaker was covered with perforated polythene paper and placed in an undisturbed position to ensure the slow solvent evaporation at room temperature. Seeds were obtained within 20 days due to spontaneous nucleation in supersaturated solution of CAE. The size of the crystals depends on the amount of material available in the solution which in turn is decided by the 
solubility of the material in solvent.

An electron is transferred from the carbonyl group of ethanoate to the amine group of aromatic amine forms the anilinium ethanoate ionic crystal. The reaction mechanism of the grown CAE was shown in Figure 1.

Transparent and good quality seeds were selected for growth. After 25 days optically good colorless single crystal of dimension $25 \times 29 \times 10 \mathrm{~mm}^{3}$ was grown as shown in Figure 2. The grown CAE crystal has been subjected to various characterization techniques.

\section{Result and Discussion}

\subsection{X-Ray Diffraction Studies}

Suitable crystals of P-Chloroanilinium ethanoate were selected for single crystal $\mathrm{X}$-ray diffraction analysis. The selected crystal was employed in Bruker D8 VENTURE SC-XRD with Mo and $\mathrm{Cu}$ radiation. Bruker allows the combination of two X-ray sources $(\mathrm{Mo}, \mathrm{Cu})$ with a highly accurate goniometer. The PHOTON

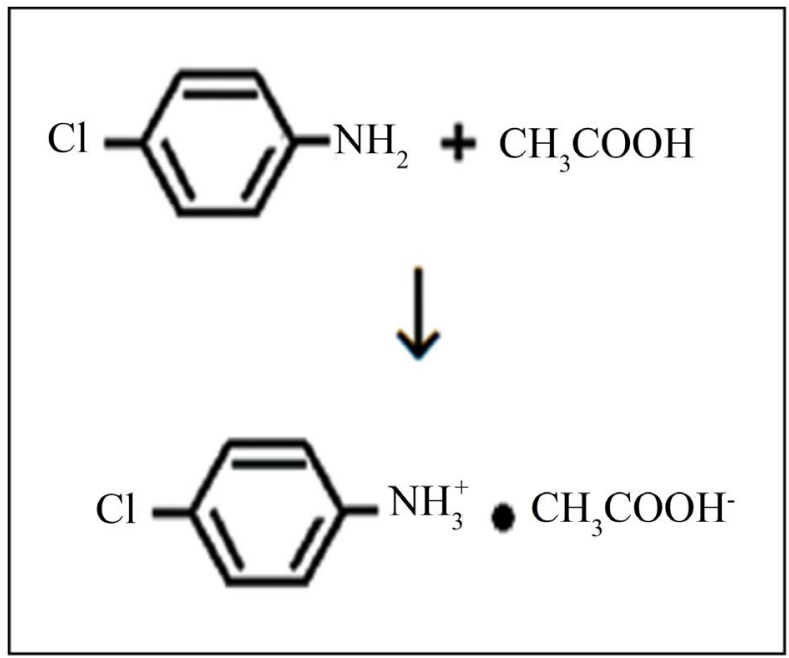

Figure 1. Reaction scheme of a grown CAE.

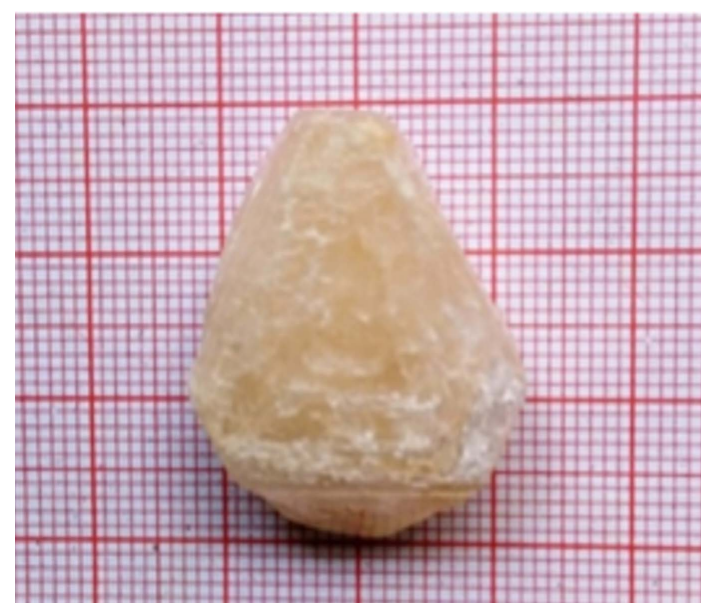

Figure 2. Photograph of a grown CAE single crystal. 
100 CMOS detector is optimized for both $\mathrm{Mo}(\mathrm{Ka})$ and $\mathrm{Cu}(\mathrm{Ka})$ radiations. Accurate unit cell parameters were refined by the selection of 150 reflections out of 161 reflections. Data collection was performed by using the APEX3 software program. This CAE crystal belongs to orthorhombic symmetry with space group $\mathrm{P}_{21}$. The cell dimensions are $a=7.42 \AA, b=8.68 \AA, c=9.32 \AA, \alpha=\beta=\gamma=90^{\circ}, V$ $=600 \AA^{3}$, which exhibit interesting ferroelectric, piezoelectric and triboluminescence properties. The possible correlation between these properties of organic single crystals belonging to the orthorhombic system has already been investigated and was found to be structure sensitive [16]. Table 1 shows the crystallographic data of CAE.

\subsection{FT-Infrared and FT-Raman Spectral Studies}

A Perkin Elmer-Paragon Fourier Transform Infrared Spectrometer was used to record the FTIR spectrum of CAE. The spectrum was recorded by the KBr pellet technique between the range $4000 \mathrm{~cm}^{-1}$ to $400 \mathrm{~cm}^{-1}$ as shown in Figure 3 . Fourier

Table 1. The crystallographic data of CAE.

\begin{tabular}{cc}
\hline Parameters & Values \\
\hline$a(\AA)$ & $7.42 \AA$ \\
$b(\AA)$ & $8.68 \AA$ \\
$c(\AA)$ & $9.32 \AA$ \\
$\alpha\left(^{\circ}\right)$ & $90^{\circ}$ \\
$\beta\left(^{\circ}\right)$ & $90^{\circ}$ \\
$\gamma\left({ }^{\circ}\right)$ & $90^{\circ}$ \\
Volume & $600 \AA^{3}$ \\
Crystal system & Orthorhombic \\
Space group & $\mathrm{P}_{21}$ \\
\hline
\end{tabular}

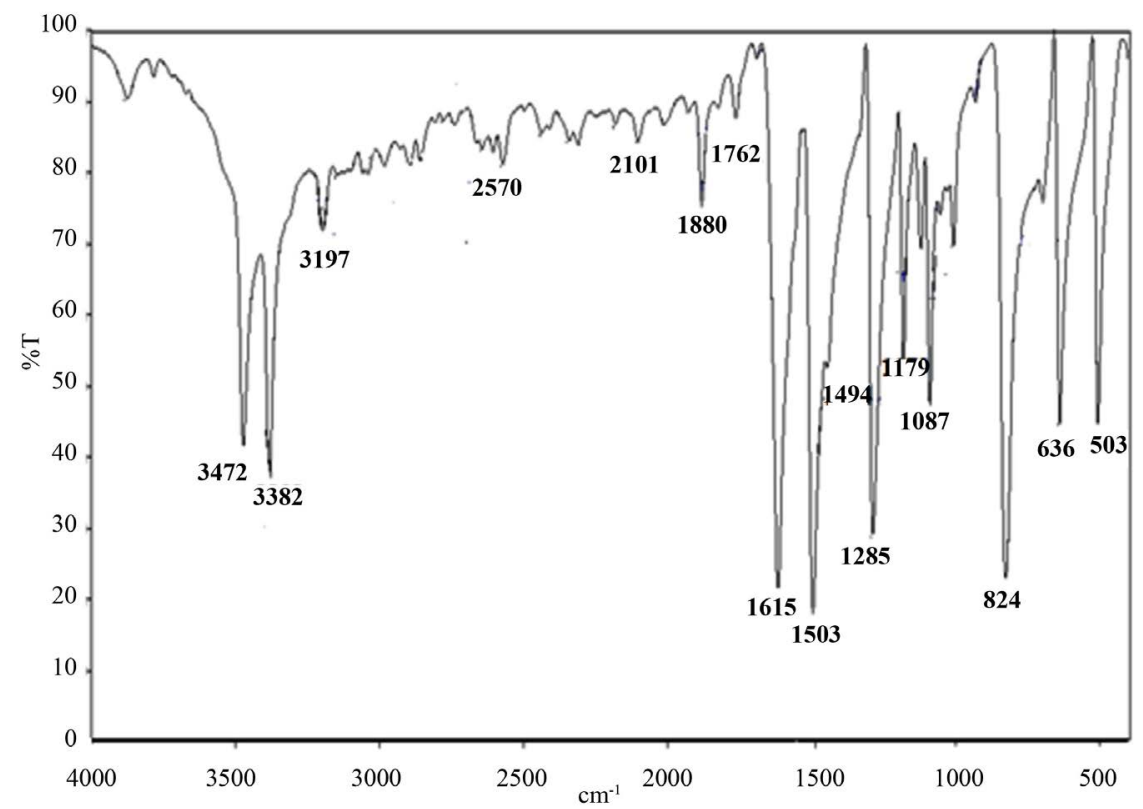

Figure 3. FTIR spectrum of CAE. 
Transform Raman spectrum of CAE was recorded in the region of $4000-500$ $\mathrm{cm}^{-1}$ by using Bruker RFS 27 FT-Raman spectrometer equipped with an FRA-106. FT-Raman accessory in the Stokes region using the $1064 \mathrm{~nm}$ line of an $\mathrm{Nd}$ : YAG laser for excitation operating at $200 \mathrm{~mW}$ power with a resolution up to $2 \mathrm{~cm}^{-1}$. The FT-Raman spectrum of CAE is shown in Figure 4. The existence of one or more aromatic rings in a structure was normally readily determined from the $\mathrm{C}-\mathrm{H}$ and $\mathrm{C}=\mathrm{C}-\mathrm{C}$ ring related vibrations. The $\mathrm{C}-\mathrm{H}$ stretching occurs at 3472 $\mathrm{cm}^{-1}$ and was typically exhibited as a multiplicity of weak to moderate bands compared with the aliphatic $\mathrm{C}-\mathrm{H}$ stretch. In the infrared spectrum, the peak at $3472 \mathrm{~cm}^{-1}$ and $3382 \mathrm{~cm}^{-1}$ corresponds to $\mathrm{C}-\mathrm{H}$ stretching vibration but in Raman spectra the peak at $3382 \mathrm{~cm}^{-1}$ and $3059 \mathrm{~cm}^{-1}$. The other most important set of bands are the aromatic ring vibrations cantered around $1600 \mathrm{~cm}^{-1}$ and 1500 $\mathrm{cm}^{-1}$, which usually appear as a pair of bands and in this work, the peaks appear at $1615 \mathrm{~cm}^{-1}$ and $1503 \mathrm{~cm}^{-1}$ for infrared and in Raman $1613 \mathrm{~cm}^{-1}$ and $1566 \mathrm{~cm}^{-1}$ confirms the ring formation. In imine group 1,4 substitution (para) of $\mathrm{C}-\mathrm{H}$ deformation vibration obtained in the region $800 \mathrm{~cm}^{-1}-840 \mathrm{~cm}^{-1}$ in this present work the peak obtained at $824 \mathrm{~cm}^{-1}$ (infrared) and $817 \mathrm{~cm}^{-1}$ (Raman). The peak at $636 \mathrm{~cm}^{-1}$ was assigned to confirm mono chlorinated aromatic $\mathrm{C}-\mathrm{Cl}$ stretching in infrared and $635 \mathrm{~cm}^{-1}$ in Raman spectral studies. A sharp peak at $1087 \mathrm{~cm}^{-1}$ in infrared and $1089 \mathrm{~cm}^{-1}$ in Raman bands gave the vibrational frequency of C-N aromatic stretching. The measured infrared and Raman peak positions and their assignments of CAE are given in Table 2.

\subsection{UV-VIS Transmission Studies}

Internal transmittance of CAE material was recorded using Perkin Elmer Lambda 35 UV-VIS spectrometer in the wavelength range of $200-1100 \mathrm{~nm}$. Optically polished crystal of $2 \mathrm{~mm}$ thickness was used for the study and the recorded spectrum was shown in Figure 5. The UV-VIS spectrum of CAE in the range of

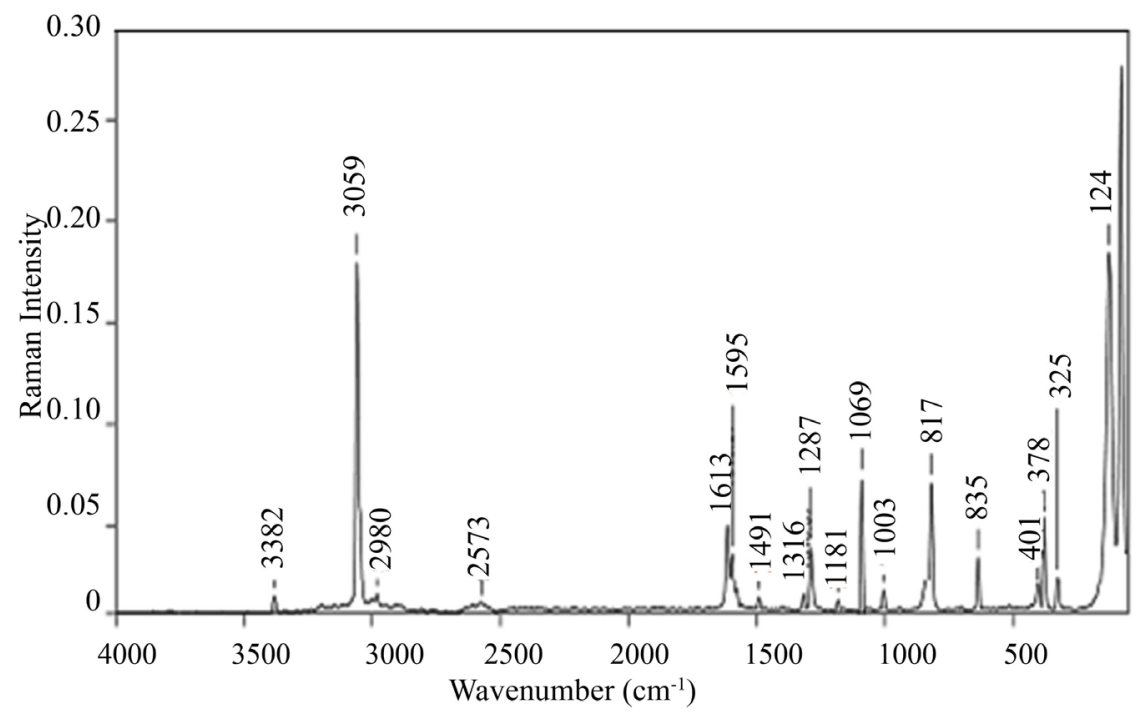

Figure 4. FT Raman spectrum of CAE. 
Table 2. The vibrational characteristics peaks of CAE.

\begin{tabular}{ccl}
\hline FTIR $\left(\mathrm{cm}^{-1}\right)$ & $F T$-Raman $\left(\mathrm{cm}^{-1}\right)$ & \multicolumn{1}{c}{ Spectral Assignments } \\
\hline 3382 & 3382 & $\mathrm{C}-\mathrm{H}$ stretching vibration \\
2982 & 2980 & $\mathrm{C}=\mathrm{C}$ stretching \\
1615 & 1613 & $\mathrm{C}=\mathrm{O}$ stretching mode \\
1503 & 1506 & $\mathrm{COO}^{-}$symmetric stretching \\
1494 & 1491 & $\mathrm{COO}^{-}$anti symmetric stretching \\
1285 & 1287 & $\mathrm{CH}_{3}$ group deformation \\
1179 & 1181 & $\mathrm{NH}_{3}$ rocking \\
1087 & 1089 & $\mathrm{C}-\mathrm{N}$ aromatic stretching \\
824 & 817 & $\mathrm{C}-\mathrm{Cl}$ stretching \\
636 & 635 & \\
\hline
\end{tabular}

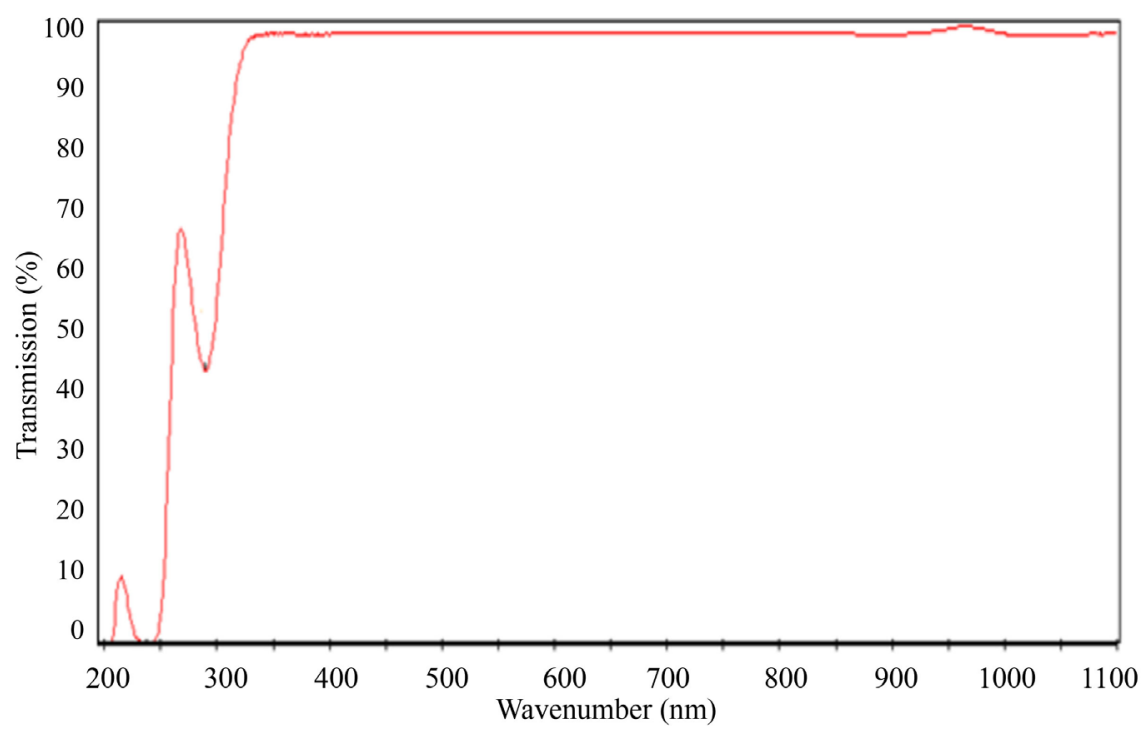

Figure 5. Transmission spectrum of CAE.

$200-238 \mathrm{~nm}$ consists of two sharp falls. The first fall at $237 \mathrm{~nm}$ interpreted as benzene $\pi \rightarrow \pi^{*}$ transition modified by the amine and nitro substituents, whereas the second fall observed at $289 \mathrm{~nm}$ arises from the electronic transition involving aniline and methyl groups [17]. At $238 \mathrm{~nm}$, the percentage of transmittance starts increasing, which shoots $99 \%$ at $337 \mathrm{~nm}$. Thus, we infer that CAE crystal was transparent in the region between $330 \mathrm{~nm}$ and $1100 \mathrm{~nm}$ and it is the key requirement for materials using for optoelectronic applications [18]. The optical absorption coefficient $(\alpha)$ was calculated from transmission spectrum using the formula,

$$
\alpha=2.3026 \frac{1}{d} \log \left(\frac{1}{T}\right)
$$

where $T$ was the transmittance and d was the thickness of the sample. From optical band gap energy was determined from,

$$
\alpha=\frac{A\left(h v-E_{g}\right)^{\frac{1}{2}}}{h v}
$$


where $E_{g}$ was the optical bandgap of the sample, $h$ was the Plank's constant, $v$ was the frequency of the incident photon and $A$ was a constant. The optical band gap energy of the grown crystal was calculated by,

$$
E_{g}=\frac{1240}{\lambda}(\mathrm{eV})
$$

where $\lambda$ is the lower cut off wavelength ( $337 \mathrm{~nm}$ ). The band gap of the grown CAE crystal was found to be $3.67 \mathrm{eV}$. Also, the optical energy band gap of CAE was evaluated by a linear plot between hv and $(\alpha h v)^{1 / 2}$ and the graph was shown in Figure 6 and is also found to be $3.64 \mathrm{eV}$, it was the same as the calculated value.

\subsection{Fluorescence Spectral Analysis}

Fluorescence spectral analysis was one of the effective methods that provide information about the fluorescence behaviors of the grown optical materials. The fluorescence emission spectrum of CAE was recorded by using Perkin Elmer LS 45. Compounds containing aromatic functional groups with low energy $\pi \rightarrow \pi^{\star}$ transition levels and highly conjugated double bond structures exhibit fluorescence. This property finds wide applications in the branches of biochemical, medical and chemical research fields for analyzing organic compounds [19]. The existence of defects shows the major impact on fluorescence materials. The grown crystals were excited at 344 and $694 \mathrm{~nm}$ to discern the photoluminescence spectrum. Figure 7 shows the emission spectra recorded at room temperature in the range of $310 \mathrm{~nm}$ to $900 \mathrm{~nm}$. The strong emission peak for CAE was observed at $344 \mathrm{~nm}$ and a weak emission spectrum observed at $695 \mathrm{~nm}$. Using the spectrum the bandgap energy of CAE was calculated as $3.61 \mathrm{eV}$. This result has coincided with the UV-VIS transmission spectrum. The emission peak energy values were found to be lower than the band gap energy of the material. Therefore, the obtained fluorescence emission might be radiative recombination of trapped electron and holes.

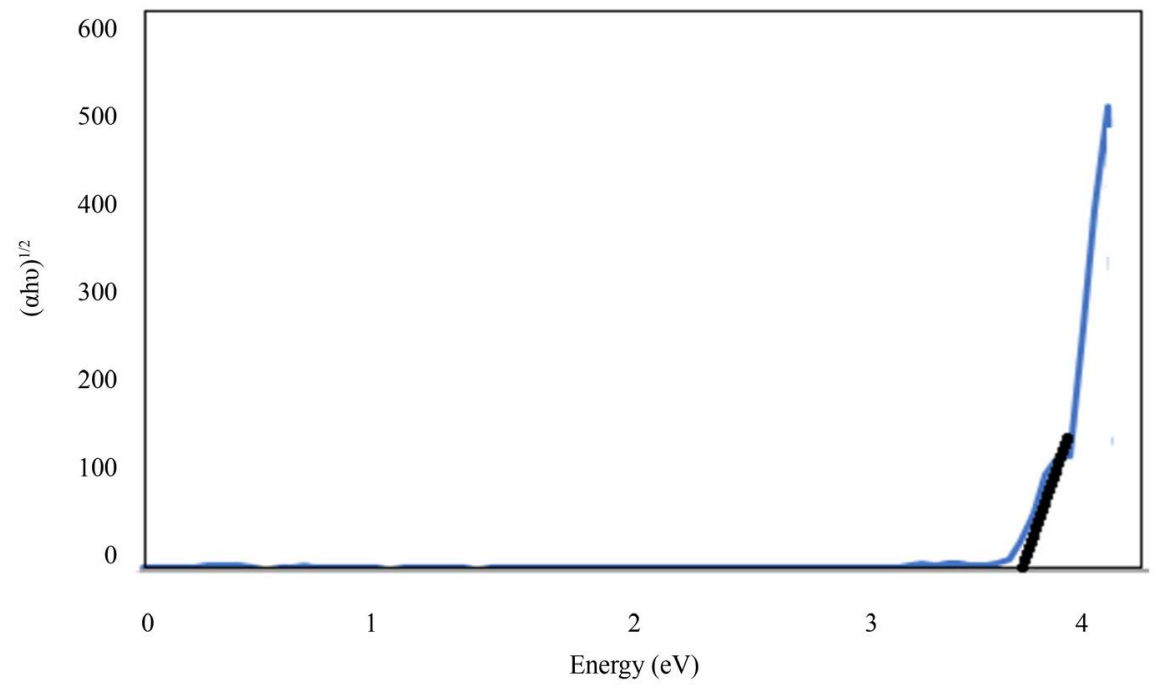

Figure 6. Tauc's plot of CAE. 


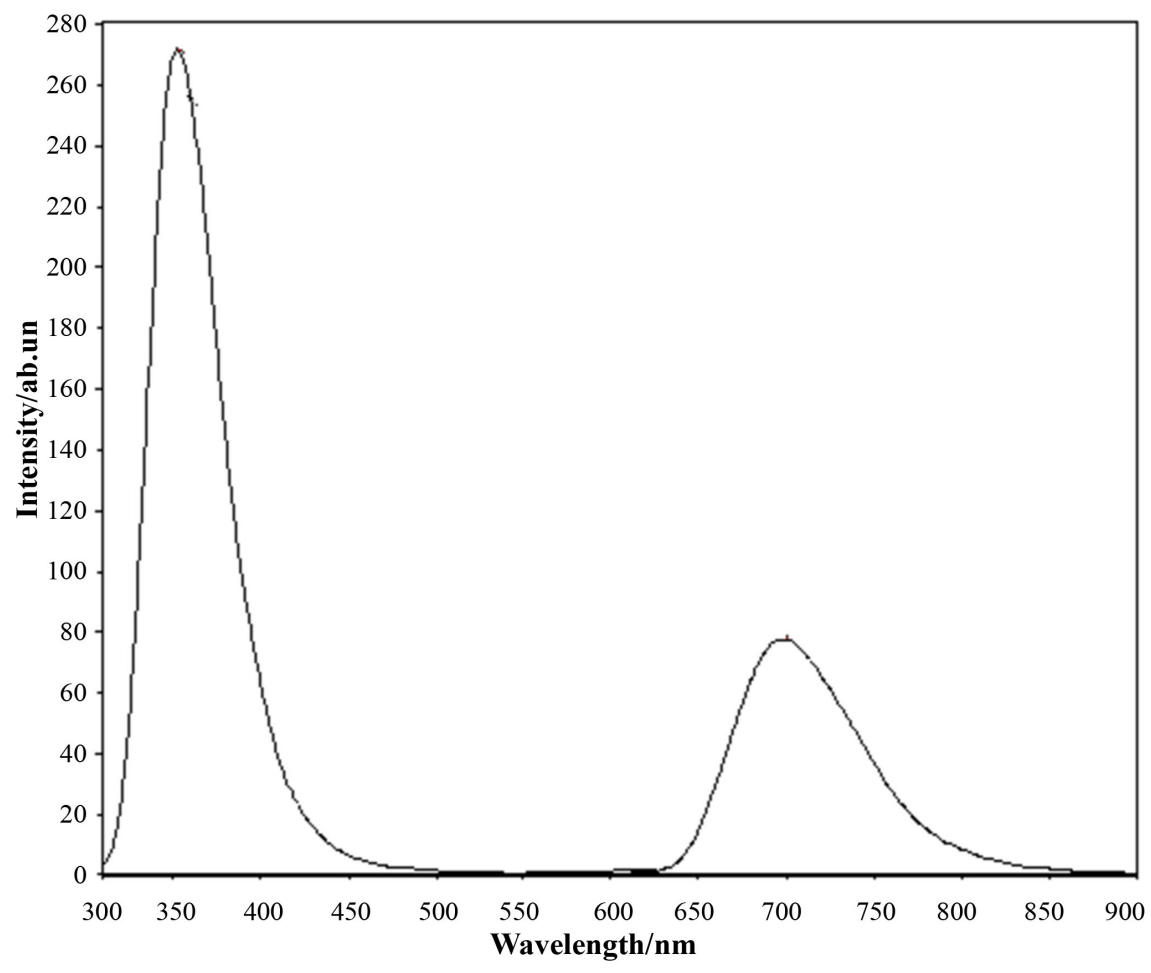

Figure 7. Fluorescence spectrum of CAE.

\subsection{Second Harmonic Generation Efficiency}

Generally, the high SHG efficiency was related to favorable molecular alignment facilitating nonlinearity. In Kurtz Perry method the crystal was ground to homogeneous powder and tightly packed in a micro capillary tube and mounted in the path of the Q-switched Nd:YAG laser beam emitting $1064 \mathrm{~nm}, 9 \mathrm{~ns}$ pulse width with a repetition rate of $10 \mathrm{~Hz}$ and $7 \mathrm{~mJ}$ powers. The second harmonic generation efficiency of the grown CAE crystal was about 1.05 times that of KDP.

\subsection{Micro Hardness Studies}

The important mechanical parameters like Vickers hardness number, elastic stiffness constant, Fracture toughness, Brittle index and yield strength of each load were determined for the grown CAE crystals using the applied load P and diagonal length $\mathrm{d}$ of the tester. Indentations were made on the flat polished (001) face of the crystal at room temperature for loads 25, 50 and $100 \mathrm{~g}$ using Vickers hardness tester fitted with diamond intender attached to an incident light microscope to study the mechanical strength of the crystal. Applied load P was varied from 25 to $100 \mathrm{~g}$ with constant indention time $10 \mathrm{~s}$. Beyond $100 \mathrm{~g}$ of the applied load cracks were observed and material chipping became significant and thus hardness test could not be carried out further. The Vickers hardness number $\left(H_{v}\right)$ of each load was calculated by,

$$
H_{v}=\frac{1.8544 P}{d^{2}}\left(\mathrm{~kg} / \mathrm{mm}^{2}\right)
$$


where 1.8544 was the constant value for diamond pyramid indenter, the applied load is $P$ and average of the two diagonal lengths of the indentations is $d$. The graph between the variations of $H_{v}$ with load $\mathrm{P}$ was plotted in Figure 8 and a plot of $\log \mathrm{P}$ versus $\log \mathrm{d}$ is shown in Figure 9. It was evident from Figure 8 that $H_{V}$ increases with increasing with load $\mathrm{P}$ due to the reverse size indentation effect [20]. The Meyers index number " $n$ " estimated from the slope of Figure 9 which indicates that CAE crystal belongs to the soft materials category [21]. The strength of the bending atom in connection with a neighbouring atom can be analyzed by Wooster's empirical formula of elastic stiffness constant and it was derived from the Vickers hardness number $\left(H_{v}\right)$. The elastic stiffness constant $\left(C_{11}\right.$ ) of each load was calculated by using the formula,

$$
C_{11}=\left(H_{v}\right)^{\frac{7}{4}}(\mathrm{GPa})
$$

The plot between load $P$ and stiffness constant $C_{11}$ for the CAE crystal was shown in Figure 10. The fracture toughness $K_{c}$ is the resistance to fracture which

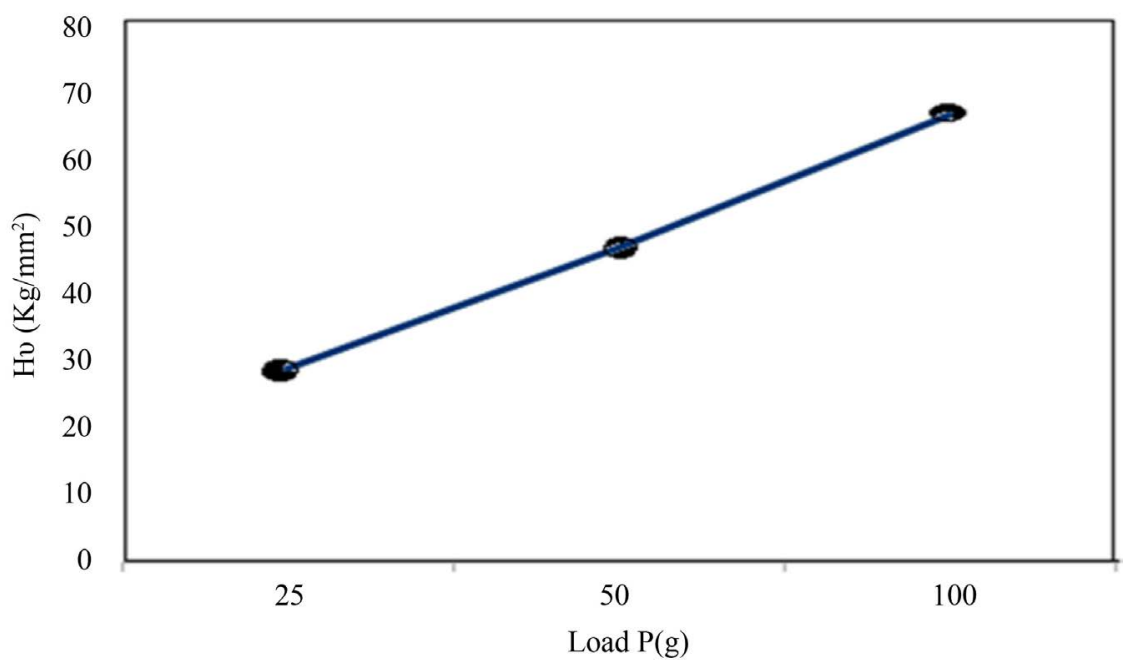

Figure 8. Vickers hardness plot of CAE.

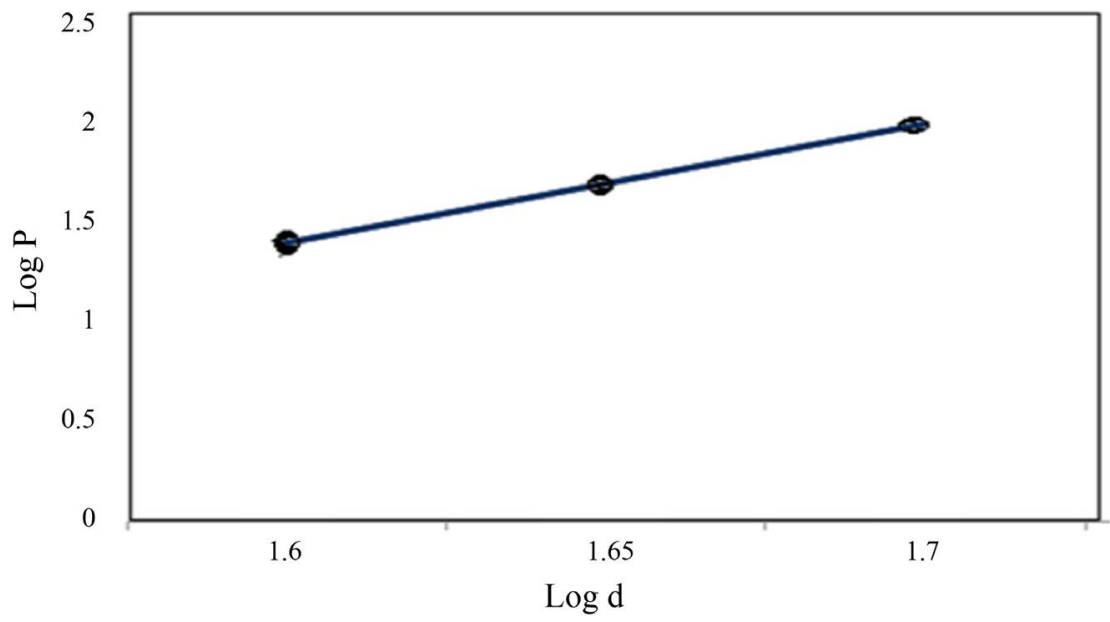

Figure 9. Work hardening coefficient plot of CAE. 


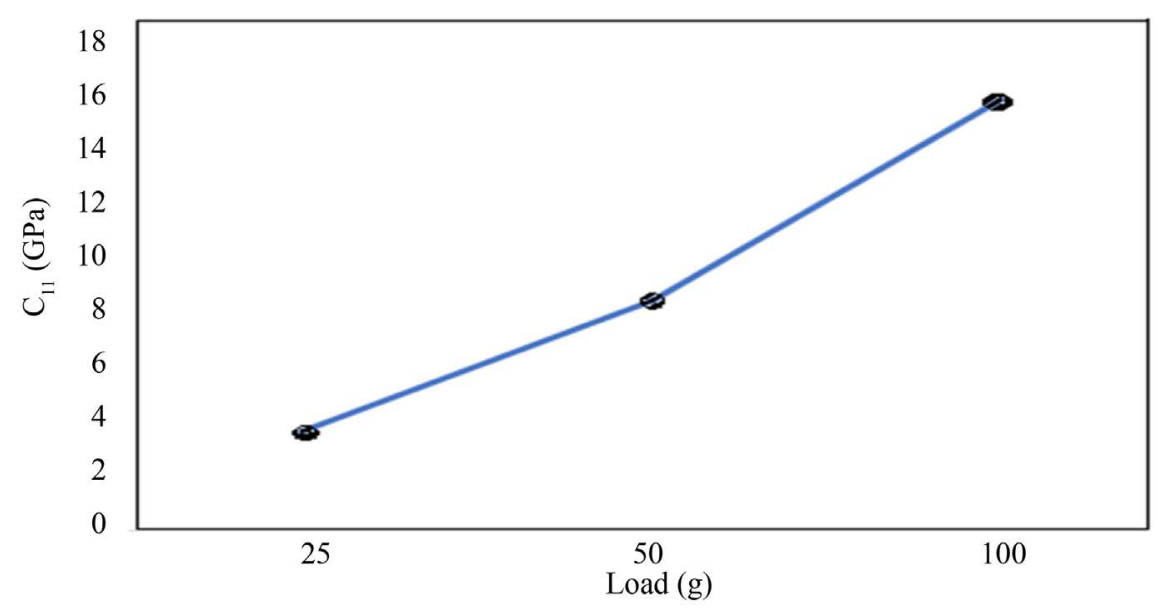

Figure 10. Plot of $P$ Vs $C_{11}$ of CAE.

envisages the toughness of the material. It also determines the intensity of the fracture stress applied under uniform loading and was given by the relation,

$$
K_{c}=\frac{P}{\beta_{o}(L)^{\frac{3}{2}}}\left(\mathrm{~kg} \cdot \mathrm{m}^{-3 / 2}\right)
$$

where $\beta_{o}$ is the indenter constant equal to 7 for the Vickers diamond pyramid indenter and $L \geq d / 2$ and the graph between $P$ and $K_{c}$ was shown in Figure 11 . The relation between hardness number $H_{v}$ and fracture toughness $K_{c}$ was known as the brittleness index Bi and it was computed by,

$$
B i=\frac{H_{v}}{K_{c}}\left(\mathrm{~m}^{1 / 2}\right)
$$

and a plot of load $P$ and brittleness index $B i$ was shown in Figure 12. From the hardness values, the Yield strength $\left(\sigma_{y}\right)$ can be calculated. The yield strength was defined as the stress at which the material begins to deform plastically and it depends on Meyer's index number $n$. For $n>2, \sigma_{y}$ can be calculated using the expression,

$$
\sigma_{y}=\frac{3-n}{2.9}\left(\frac{12.5(n-2)}{3-n}\right)^{n-2} H_{v}(\mathrm{~Pa})
$$

For $n<2$, the yield strength is calculated using the relation,

$$
\sigma_{y}=\frac{H_{v}}{3}(\mathrm{~Pa})
$$

The yield strength of each load was shown in Figure 13. The mechanical parameter values of each load of CAE were tabulated in Table 3. From this, the hardness number, elastic stiffness constant, fracture and the yield strength are increased due to the increased load but the Brittle index number was decreased.

\subsection{Thermal Analysis}

Thermo gravimetric analysis was an efficient tool to describe the decomposition 


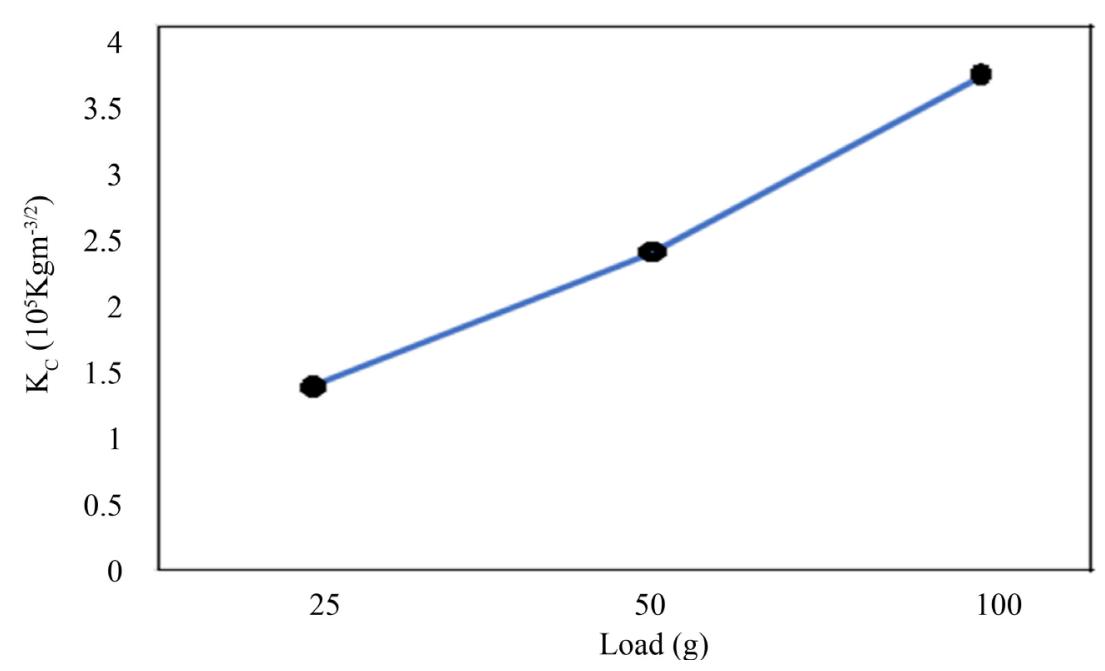

Figure 11. Plot of $P$ Vs $K_{C}$ of CAE.

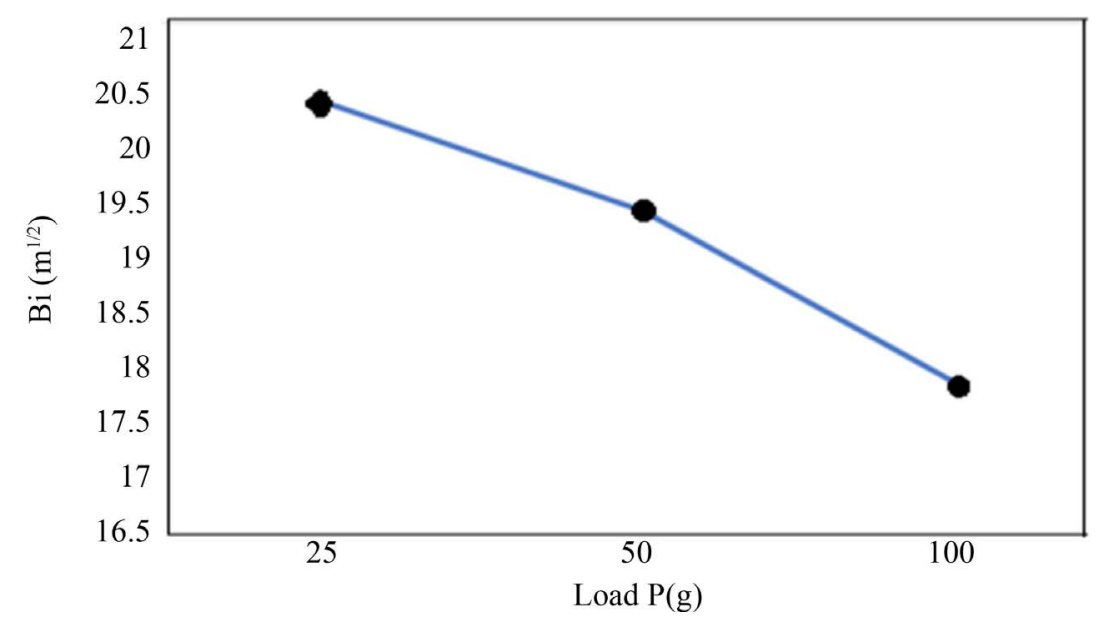

Figure 12. Plot of $P$ Vs $B i$ of CAE.

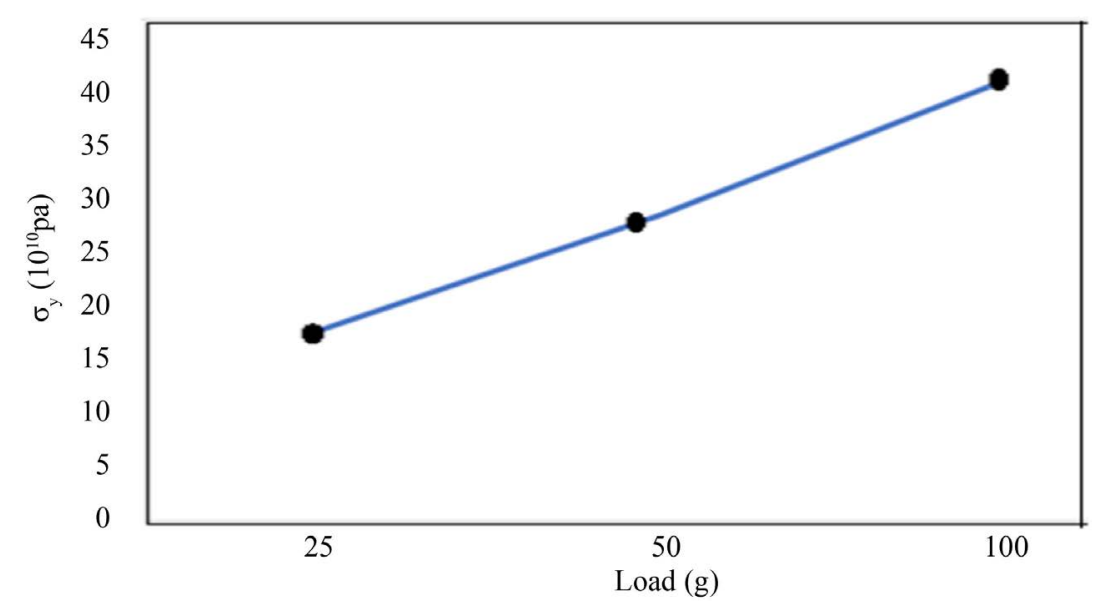

Figure 13. Plot of $P$ Vs $\sigma_{y}$ of CAE.

and phase transition in the material with temperature. The TG/DTG and TG-DSC curve was recorded by a heating rate of $10^{\circ} \mathrm{C} \mathrm{min}^{-1}$ by using NETZSCH 
STA $449 \mathrm{~F} 3$ Jupiter thermal analyzer for the temperature range from $30^{\circ} \mathrm{C}$ to $270^{\circ} \mathrm{C}$ for $6.085 \mathrm{mg}$ of a sample. The TG/DTG curve of the CAE was shown in Figure 14. The TG curve shows that the material was stable up to $73^{\circ} \mathrm{C}$ and the decomposition step was observed from $73^{\circ} \mathrm{C}$ to $189^{\circ} \mathrm{C}$ with a drastic weight loss of about $90 \%$. This weight loss could be attributed to the compound oxidation with the evaporation of $\mathrm{H}_{2} \mathrm{O}, \mathrm{CO}_{2}$ gases [22]. Finally, the residue was observed at about $1.5 \%$ at $270^{\circ} \mathrm{C}$. The sharpness of the DTG endothermic peak indicates good crystallinity of CAE.

The differential scanning calorimetry (DSC) measurement was carried out for CAE material by using a sample of $10 \mathrm{~g}$ with a thermal analyzer of Netzsch DSC 204. The DSC curve of the material was shown in Figure 15. The endothermic peaks at $73^{\circ} \mathrm{C}$ and $189^{\circ} \mathrm{C}$ are due to the decomposition process which coincided exactly with the TG/DTG curve. The shape of the peaks changing in such a way of height, breadth, and sharpness is due to the poor thermal contact of the sample and their quantity (mass) [23] [24]. The sharpness of the DSC peaks shows that the CAE sample has higher crystallinity and purity, which is useful for laser and NLO applications for temperature below $73^{\circ} \mathrm{C}$.

The TG-DSC trace of the sample is shown in Figure 16. From the TG

Table 3. Mechanical parameter values of CAE.

\begin{tabular}{cccc}
\hline & \multicolumn{3}{c}{ Load P(g) } \\
Mechanical Parameters & 25 & 50 & 100 \\
\cline { 2 - 4 } & 29.1 & 46.7 & 67.2 \\
Hardness Number $H_{V}\left(\mathrm{~kg} / \mathrm{mm}^{2}\right)$ & 3.65 & 8.41 & 15.77 \\
Elastic Stiffness constant $C_{11}(\mathrm{GPa})$ & 1.42 & 2.41 & 3.76 \\
Fracture toughness $K_{c}\left(10^{5} \mathrm{kgm}^{-3 / 2}\right)$ & 20.45 & 19.46 & 17.87 \\
Brittleness Index $B i\left(\mathrm{~m}^{1 / 2}\right)$ & 17.76 & 28.62 & 41.01 \\
Yield Strength $\sigma_{y}\left(10^{10} \mathrm{pa}\right)$ & & & \\
\hline
\end{tabular}

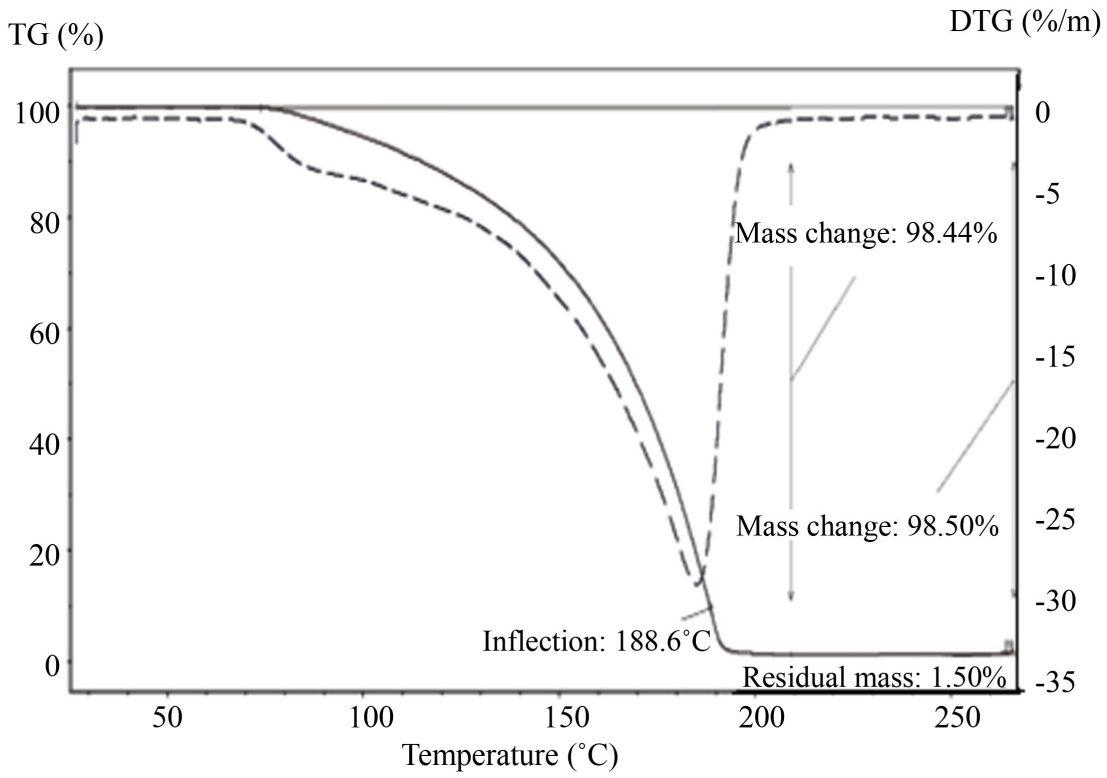

Figure 14. TG-DTG trace of CAE. 


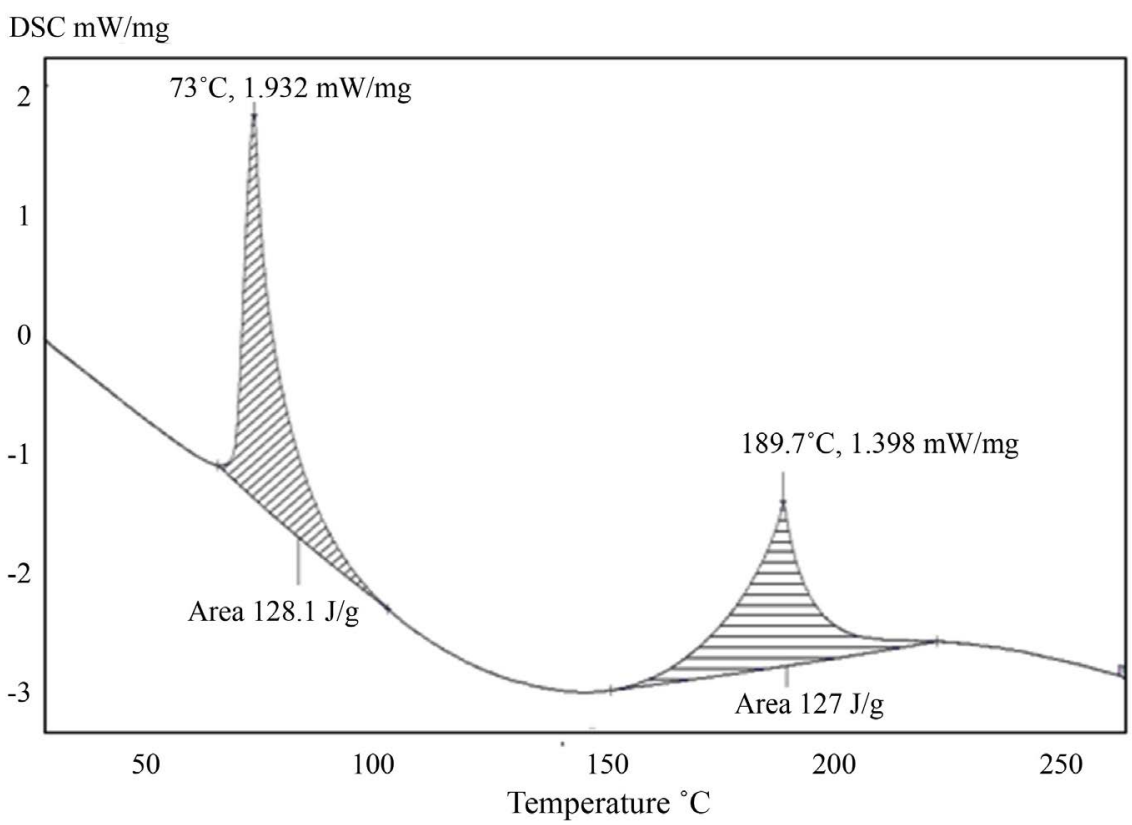

Figure 15. DSC trace of CAE.

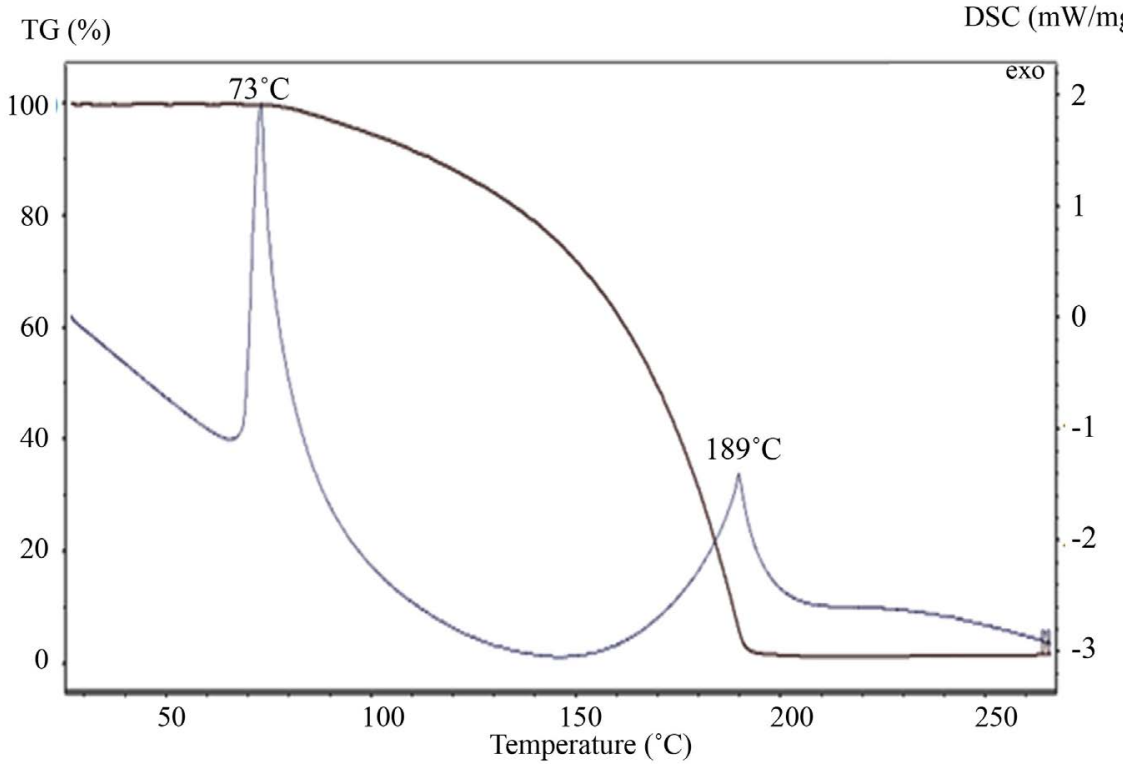

Figure 16. TG-DSC trace of CAE.

thermo-gram there was a weight loss between $73^{\circ} \mathrm{C}$ with a maximum at $189^{\circ} \mathrm{C}$. The total weight loss corresponds to $90 \%$. The weight loss clearly illustrates the melting and its subsequent evaporation. The DSC trace for heating produced two nearly equal exothermic peaks at $73^{\circ} \mathrm{C}$ and $189^{\circ} \mathrm{C}$ due to chemical reaction. The area of the peak gave the amount of heat released if it is $128.1 \mathrm{~J} / \mathrm{g}$ for the first and $127 \mathrm{~J} / \mathrm{g}$ for the second peak. Since the CAE crystals were grown by a slow evaporation method, they have taken care of omitting the occluded water, if any, during the growth by annealing the samples fairly at higher temperatures. In this report, CAE shows a phase transition at $73^{\circ} \mathrm{C}$, when the temperature was slowly 
increased from room temperature.

\section{Conclusion}

An organic ionic crystal of CAE was synthesized by the condensation process and grown by slow evaporation solution growth method at room temperature. The unit cell parameters were confirmed by single crystal XRD studies which indicates that it belongs to the orthorhombic crystal system with space group $\mathrm{P}_{21}$. Functional groups of the final product were analyzed by a comparative spectrum of both FTIR, FT Raman analyses. The lower cut off wavelength and transmission from the entire visible range was confirmed by the UV-VIS transmission spectrum and the band gap was found to be $3.67 \mathrm{eV}$. The powder second harmonic generation efficiency was 1.05 times that of KDP. Fluorescence spectral analysis provides information about the luminescence behavior of the grown optical materials. Emission peak energy values were found to be lower than the band gap energy of the material. From Vickers's hardness study the hardness number increases with increasing with load which indicates that CAE crystal belongs to soft material category. The sharpness of the DSC/DTG peaks shows that the CAE sample has higher crystallinity and purity, which was useful for laser and $\mathrm{NLO}$ applications below $73^{\circ} \mathrm{C}$ for its temperature.

\section{Acknowledgements}

The authors acknowledge Indian Institute of Science, Bangalore for NLO studies and Sophisticated Analytical Instrument Facility, IIT, Chennai for recording Single crystal data, FT-Raman and Thermal Analysis. The authors are thankful to Archbishop Casimir Instrumentation Centre, St. Joseph's College, Tiruchirappalli for UV, FT-IR, Fluorescence and Micro hardness tests.

\section{Conflicts of Interest}

The authors declare no conflicts of interest regarding the publication of this paper.

\section{References}

[1] Thirupugalmani, K., Karthick, S., Shanmugam, G., Kannan, V., Sridhar, B., Nehru, K. and Brahadeeswaran, S. (2015) Second and Third Order Nonlinear Optical and Quantum Chemical Studies on 2-Amino-4-Picolinium-Nitrophenolate-Nitrophenol: A phase matchable organic Single Crystal. Optical Materials, 49, 158-170. https://doi.org/10.1016/j.optmat.2015.09.014

[2] Goetz, K.P., Vermeulen, D., Payne, M.E. Christian Kloc, L.E., McNeil, O.D. and Jurchescu, J. (2014) Charge-Transfer Complexes: New Perspectives on an Old Class of Compounds. Journal of Material Chemistry, 2, 3065-3076. https://doi.org/10.1039/C3TC32062F

[3] Selvakumar, S. and Leo Rajesh, A. (2016) Growth and Characterization of Cyclohexylamine Hydrogen Phthalate Hemihydrate Nonlinear Optical Single Crystals. Journal of Material Science and Material Electronics, 27, 7509-7517. https://doi.org/10.1007/s10854-016-4730-Z 
[4] Miyazawa, T., Shimanouchi, T. and Mizushima, S. (1958) Characteristic Infrared Bands of Monosubstituted Amides. Journal of Chemistry and Physics, 24, 408-418. https://doi.org/10.1063/1.1742489

[5] Vijayalakshmi, M., Rajan Babu, D. and Ezhil Vizhi, R. (2015) Synthesis, Growth and Characterization of Organic Nonlinear Optical Material: 4-Chloroaniline. Journal of Indian Chemical Society, 92, 815-817.

[6] Srinivasan, P., Kanagasekaran, T., Gopalakrishnan, R., Bhagavannarayana, G. and Ramasamy, P. (2006) Studies on the Growth and Characterisation of L-Asparaginium Picrate: A Novel Nonlinear Optical Crystal. Crystal Growth and Design, 6, 1663-1670. https://doi.org/10.1021/cg060094+

[7] Pauling, L. (1960) The Nature of the Chemical Bond. Cornell University Press, New York.

[8] Silambarasan, A., Rajesh, P. and Ramasamy, P. (2014) Crystal Growth, Optical and Thermal Studies of 4-Nitroaniline 4-Aminobenzoic Acid: A Fluorescent Material. Chemical Science Review and Letters, 2, 521-525.

[9] Jothi, L., Ramesh Babu, R. and Ramamurthi, K. (2014) Synthesis, Growth and Characterization of Organic Nonlinear Optical Single Crystals of 4-Bromo-4'-Methyl Benzylidene Aniline. Journal of Minerals and Material Characterisation and Engineering, 2, 308-318. https://doi.org/10.4236/jmmce.2014.24036

[10] Srinivasan, K., Biravaganesh, R. Gandhimathi, R. and Ramasamy, P. (2002) Growth and Characterization of 4-Nitro-4'-Methyl Benzylidene Aniline Single Crystals. Journal of Crystal Growth, 236, 381-392. https://doi.org/10.1016/S0022-0248(01)02202-3

[11] Nixon Azariah, A., Haja Hameed, A.S., Thenappan, T., Noel, M. and Ravi, G. (2004) Crystal Growth and Characterization of 4-Nitro-4'-Methoxy Benzylidene Aniline. Journal of Material Chemistry and Physics, 88, 90-96. https://doi.org/10.1016/j.matchemphys.2004.06.024

[12] Leela, S., Ramamuthi, K. and Bhagavannarayana, G. (2009) Synthesis, Growth, Spectral, Thermal, Mechanical and Optical Properties of 4-Chloro-4-dimethylamino-benzylidene Aniline: A Third Order Nonlinear Optical Material. Spectrochimica Acta Part A, 74, 78-83. https://doi.org/10.1016/j.saa.2009.05.028

[13] Jothi, L., Vasuki, G., Ramesh Babu, R. and Ramamurthi, K. (2014) Synthesis, Crystal Growth and Characterization of Organic NLO Material: 4-Bromo-4-Hydroxybenzylideneaniline. Optik, 125, 2017-2021. https://doi.org/10.1016/j.ijleo.2013.07.170

[14] Xu, D. and Xue, D. (2006) Chemical Bond Analysis of the Crystal Growth of KDP and ADP. Journal of Crystal Growth, 286, 108-113. https://doi.org/10.1016/j.jcrysgro.2005.09.040

[15] Anitha, R., Athimoolam, S., Gunasekaran, M. and Anitha, K. (2014) X-Ray, Vibrational Spectra and Quantum Chemical Studies on a New Semiorganic Crystal: 4-Chloroanilinium Perchlorate. Journal of Molecular Structure, 1070, 115-125. https://doi.org/10.1016/j.molstruc.2014.07.035

[16] Uthayarani, K., Sankar, R. and Shashidharan Nair, C.K. (2008) Growth, Spectral and Thermal Properties of KAP Single Crystals in the Presence of DL-Alanine and L-Methionine Amino Acid Dopants. Crystal Research Technology, 43, 733-739. https://doi.org/10.1002/crat.200711091

[17] Coates, J. and Meyers, R.A. (Eds.) (2000) Interpretation of infrared spectra, A Practical Approach, Encyclopedia of Analytical Chemistry. John Wiley \& Sons Ltd, Chichester. 
[18] Bhat, H.L. (1994) Growth and Characterization of Some novel Crystals for Nonlinear Optical Applications. Journal of Material Science, 17, 1233-1249. https://doi.org/10.1007/BF02747223

[19] Willard, H.H., Merritt, L.L., Settle, J.A. and Settle, F.A. (1986) Instrumental Methods of Analysis. 7th Edition, Wadsworth Publishing Company, Belmont.

[20] Sangwal, K. (2000) On the Reverse Indentation Size Effect and Microhardness Measurement of Solids. Journal of Material Chemistry and Physics, 63, 145-152. https://doi.org/10.1016/S0254-0584(99)00216-3

[21] Onitch, E.M. (1956) The Present Status of Testing the Hardness of Materials. Microscope, 95, 12-14.

[22] Souza, J.L., Santos, A.F., Polese, L., Crespi Marisa, S. and Ribeiro, C.A. (2007) Thermal Behaviour of the Maleic Anhydride Modified Poly(3-hydroxybutyrate). Journal of Thermal Analysis and Calorimetry, 87, 673-677. https://doi.org/10.1007/s10973-006-7852-3

[23] Hatakeyama, T. and Liu, Z. (1998) Handbook of Thermal Analysis. Wiley, Chichester.

[24] Gabbot, P. (2008) Chapter 1: A Practical Introduction to Differential Scanning Calorimetry. In: Gabbot, P., Ed., Principles and Applications of Thermal Analysis, Blackwell Publishing Ltd., Oxford, 18-19. 